\title{
Attitudes, beliefs, and perceptions of caregivers and rehabilitation providers about disabled children's sleep health: a qualitative study
}

Xiaoli Chen ${ }^{1 *}$, Bizu Gelaye ${ }^{1}$, Juan Carlos Velez ${ }^{2}$, Micah Pepper ${ }^{2}$, Sara Gorman ${ }^{3}$, Clarita Barbosa ${ }^{2}$, Ross D Zafonte ${ }^{4}$ Susan Redline ${ }^{5,6}$ and Michelle A Williams ${ }^{1}$

\begin{abstract}
Background: Children with disabilities are more likely to have sleep disturbances than children without disabilities. Identifying attitudes, beliefs, knowledge, and perceptions of caregivers and health professionals is essential in developing effective intervention programs to improve disabled children's sleep health. However, no such qualitative data about adults who have key roles in the life and daytime activities of children with disabilities are available. This qualitative study aimed to understand attitudes, beliefs, knowledge, and perceptions about disabled children's sleep hygiene among caregivers and rehabilitation providers of children with disabilities.
\end{abstract}

Methods: Twenty seven adults, including nine primary caregivers and eighteen rehabilitation providers, participated in five focus group discussions between September and December 2012 at the Rehabilitation Center in Punta Arenas, Chile. A trained facilitator guided focus group discussions using a semi-structured script. Audiotapes and transcripts of focus group discussions were reviewed and analyzed for recurrent themes.

Results: Participants identified seven themes related to children's sleep hygiene: lifestyle behaviors, family factors, children's disabilities and/or comorbidities, environmental factors, adults' responsibilities for children's sleep, perception of good sleep, and parental distress about children's sleep problems. While both caregivers and rehabilitation providers recognized the importance of sleep for children's health and functioning, they differed in their understanding of how sleep hygiene practices influence sleep. Rehabilitation providers recognized the negative influence of electronics on sleep and the positive influence of sleep routines. In contrast, caregivers reported use of television/movie watching and stimulants as coping strategies for managing children's sleep problems.

Conclusions: Caregivers may benefit from better understanding the influence of electronics and stimulant use on child sleep health. Rehabilitation providers are well positioned to provide educational messages to both children and caregivers in order to change their attitudes, perceptions, and practices surrounding sleep. These qualitative data are valuable in developing intervention programs aimed at improving sleep health among children with disabilities.

Keywords: Child, Disability, Sleep hygiene, Parent, Health care provider, Focus group

\section{Background}

At least 93 million children are living with disabilities worldwide [1]. Children with disabilities such as attentiondeficit and/or hyperactivity disorder (ADHD) are more likely to have sleep disturbances than children without disabilities [2-9], and may warrant particular attention for

\footnotetext{
* Correspondence: xchen@hsph.harvard.edu

'Department of Epidemiology, Harvard School of Public Health, Boston, MA 02115, USA

Full list of author information is available at the end of the article
}

health promotion and disease prevention. Identifying attitudes, beliefs, knowledge, and perceptions of caregivers and health professionals who treat children with disabilities is essential in developing effective intervention programs to improve children's sleep health. To our knowledge, no such qualitative data about adults who have key roles in the life and daytime activities of children with disabilities are available. The lack of such qualitative data about children's sleep among caregivers and health professionals may contribute to the persistent high prevalence of sleep 
disturbances in disabled children. Since successful interventions should reflect the views of targeted populations [10], focus groups are commonly used because they can efficiently explore the attitudes, beliefs, and perceptions of the participants

In this qualitative study, we conducted focus group interviews about children's sleep with primary caregivers and rehabilitation providers of children with disabilities. The aims of this study were to: 1) understand the attitudes, beliefs, knowledge, and perceptions of caregivers and rehabilitation providers of children with disabilities regarding children's sleep; 2) identify factors that could facilitate or impair children's sleep hygiene; and 3) identify areas for intervention and improvement of children's sleep health.

\section{Methods}

\section{Participants}

The Chile Pediatric and Adult Sleep and Stress Study (CPASS) was conducted in the Patagonia Region of Chile. The study was established in September 2012 at the Centro de Rehabilitacion Club de Leones Cruz del Sur in Punta Arenas, Chile. The present qualitative study was conducted between September and December 2012 at the center.

Using a recruitment script, a research staff member approached primary caregivers of children with disabilities when caregivers checked in for their children's appointment. Children with disabilities were those who used assistive devices and/or received routine clinical care at the center for their chronic disorders such as speech and/or motor delay, ADHD, or other types of mental disorders including Down syndrome and autism. A recruitment flyer was posted in the staff lounge asking rehabilitation providers to contact the research staff if they were interested in participating in the study. Nine adult caregivers aged $\geq 18$ years who spoke and read Spanish and who were without intellectual disabilities participated in 2 focus group discussions (4-5 participants per group). Three additional focus groups were conducted among 18 rehabilitation providers who cared for children with disabilities, including physicians, phys$\mathrm{ical} /$ speech therapists, psychologists, and special education teachers (6 participants per group).

This study was approved by the institutional review boards of Centro de Rehabilitacion Club de Leones Cruz del Sur (IRB \# 016) in Punta Arenas, Chile and Harvard School of Public Health (IRB \# 22797-101) in Boston, USA. All participants provided written informed consent.

\section{Focus groups}

All focus group discussion sessions were held in a meeting room at the center. Before the start of discussions, participants completed a brief survey providing information on sociodemographics, sleep medicine training background (for rehabilitation providers only), and the number of years that caregivers had been taking care of, or rehabilitation providers had been working with, children with disabilities. At the beginning of each session, a trained facilitator who was a psychologist at the center explained the purpose of the study, and then conducted semistructured sessions using a discussion guide developed by the research team. Of note, the facilitator was not a member of the research team. A trained note-taker took the discussion notes. For each idea discussed, general openended questions were followed by probing questions.

\section{Data analysis}

All focus group discussions were digitally audio-recorded and transcribed verbatim by a professional transcriber. Audio recordings were translated, transcribed, and annotated to clarify linguistic and cultural information. One research team member who was bilingual in English and Spanish assured the accuracy of the translation of the transcripts. The process of triangulation was used to read and code the transcripts to enhance the quality and credibility of qualitative analyses [11]. Two researchers coded the transcripts independently using thematic codes consistent with original aims of the study. The method of repetition was used to identify themes, while cutting and sorting processes were applied to code the transcripts [12]. Disagreements about the meanings of participants' comments were resolved through discussion and consensus. The final coding schemes were applied to all transcripts. To establish inter-rater reliability between the transcript coders, intra-class correlation coefficient (ICC) was calculated based on the method of Shrout and Fleiss [13]. Thematic analyses were conducted of participants' comments and discussions about their attitudes, beliefs, knowledge, and perceptions of children's sleep. To protect the identify of participants, pseudonyms are used.

\section{Results}

\section{Participants' characteristics}

The average age of focus group participants was 43.0 (range: 25.2-64.2) years for caregivers and 35.4 (range: 24.2-49.3) years for rehabilitation providers, respectively. All caregivers were women (8 mothers and 1 grandmother), 1 had a middle school degree, 5 had high school degrees, and 3 had college degrees (Table 1). Five caregivers were housewives, 3 had full-time jobs, and 1 caregiver was unemployed. Caregivers reported having taken care of children for an average of 8.5 (range: 6-13) years. Rehabilitation providers reported having worked with disabled children for an average of 6.3 (range: 1-12) years. Eight out of 18 rehabilitation providers reported professional experience with sleep medicine or sleep health hygiene; only 2 had sleep medicine training. 
Table 1 Characteristics of $\mathbf{2 7}$ focus group participants

\begin{tabular}{|c|c|c|c|c|c|}
\hline Focus group & $\begin{array}{l}\text { Number of } \\
\text { participants }\end{array}$ & Mean age (range), years & Gender & Education status & Employment status \\
\hline Group 1 & 4 caregivers & $39.7(25.2-48.4)$ & 4 women & $\begin{array}{l}1 \text { had a middle school degree, } \\
1 \text { had a high school degree, } \\
2 \text { had college degrees }\end{array}$ & $\begin{array}{l}2 \text { were housewives, } 2 \text { had } \\
\text { full-time jobs }\end{array}$ \\
\hline Group 2 & 5 caregivers & $46.1(34.5-64.2)$ & 5 women & $\begin{array}{l}4 \text { had high school degrees, } \\
1 \text { had a college degree }\end{array}$ & $\begin{array}{l}3 \text { were housewives, } 1 \text { was } \\
\text { unemployed, } 1 \text { had a full-time job }\end{array}$ \\
\hline Group 3 & $\begin{array}{l}6 \text { rehabilitation } \\
\text { providers }\end{array}$ & $32.5(24.3-46.9)$ & 3 men, 3 women & 6 had college degrees & $\begin{array}{l}5 \text { had full-time jobs, } 1 \text { had a } \\
\text { part-time job }\end{array}$ \\
\hline Group 4 & $\begin{array}{l}6 \text { rehabilitation } \\
\text { providers }\end{array}$ & $36.5(26.8-43.4)$ & 3 men, 3 women & 6 had college degrees & 6 had full-time jobs \\
\hline Group 5 & $\begin{array}{l}6 \text { rehabilitation } \\
\text { providers }\end{array}$ & $34.9(24.2-49.3)$ & 2 men, 4 women & $\begin{array}{l}3 \text { had technical school degrees, } \\
3 \text { had college degrees }\end{array}$ & $\begin{array}{l}5 \text { had a full-time job, } 1 \text { had a } \\
\text { part-time job }\end{array}$ \\
\hline
\end{tabular}

\section{Major themes}

In this study, the inter-rater ICC value was 0.90 , indicating excellent inter-rater reliability between the two transcript coders. Seven themes were identified as risk factors for children's sleep (Table 2; Table 3 for representative quotations): 1) lifestyle factors; 2) family factors; 3) children's disability/disease-related factors; 4) environmental factors; 5) adults' responsibilities for children's sleep; 6) perceptions of good sleep; 7) parental distress about children's sleep problems.

\section{Lifestyle factors}

Participants in all focus groups discussed how lifestyle behaviors affected children's sleep. Five of 9 caregivers (56\%) and 11 of 18 rehabilitation providers (61\%) stated that children's routines, family/school schedules or rules, and individual preferences affected children's sleep patterns.

Participants also discussed the associations between physical activity and sleep. Several participants believed that physical activity was related to children's sleep, and sleep medicine could help children with sleep problems due to lack of daytime activity. Notably, several participants believed that children's sleep health was affected by the time children spent watching television, playing video games, and using computers/internet and other electronic devices. One mother commented: "Yes, he wakes up on his own at that time, most of the time I am sleeping at that time and he is sitting on the couch watching TV. It is not hunger or anything else, it is the TV".

Participants also mentioned the associations between diet and/or hunger and children's sleep. Approximately $17 \%$ of rehabilitation providers noted that modern lifestyle changes such as consumption of coffee and soft drinks were connected with children's sleep. However, no caregivers mentioned stimulant use when discussing sleep-related risk factors.

\section{Family factors}

Most participants believed that family routines, parents' work schedules, and their capacity to accommodate the needs of children with disabilities could affect children's sleep. Several rehabilitation providers discussed the potential effect of adapting activities and developing routines to accommodate the special needs for improving sleep health among children with disabilities. Overall, participants recognized that various family factors were related to child sleep, highlighting the importance of healthy sleep habits (e.g., establishing a soothing presleep routine) in enhancing children's sleep health.

\section{Children's disability/disease-related factors}

Many rehabilitation providers (78\%) stated that diagnosisspecific features and comorbid conditions were related to children's sleep. Two-thirds of rehabilitation providers also expressed their concern about side effects of medications on child sleep; 1 caregiver mentioned this.

Eight caregivers (89\%) reported that their children had sleep problems such as nightmares, teeth grinding, snoring, talking/noises during sleep, and nocturnal awakening. As a mother described: "My kids have nightmares, they talk and wake up scared, there aren't any other sounds, they only speak once in a while, they sit up but that's it, sometimes they wake up crying, the one in the middle is always more scared." Another mother stated: "He sucks his tongue, grinds his teeth and snores, makes noises with his mouth, I wake him up sometimes because I think that he ruins his teeth." Overall, most caregivers were aware of their children's sleep problems, and expressed concern about children's sleep health.

\section{Environmental factors}

Several participants believed that environmental factors including light, noise, and sleeping space could affect bedtime and sleep quality. Some participants mentioned the summer sunlight, especially in the Magellan Region 
Table 2 Focus group participants' attitudes, beliefs, and perceptions about factors related to children's sleep

\begin{tabular}{|c|c|c|c|c|}
\hline Theme & Code & $\begin{array}{c}\text { Total quotes } \\
\text { (total: 27) } \\
\mathrm{N}(\%)\end{array}$ & $\begin{array}{c}\text { Caregivers } \\
\text { (total: 9) } \\
\text { N (\%) }\end{array}$ & $\begin{array}{c}\text { Rehabilitation providers } \\
\text { (total: 18) } \\
\mathrm{N}(\%)\end{array}$ \\
\hline \multirow[t]{5}{*}{ Lifestyle factors } & Routine/rule/individual preference & $16(59.3 \%)$ & $5(55.6 \%)$ & $11(61.1 \%)$ \\
\hline & Physical activity & $8(29.6 \%)$ & $2(22.2 \%)$ & $6(33.3 \%)$ \\
\hline & Screen time & $4(14.8 \%)$ & $1(11.1 \%)$ & $3(16.7 \%)$ \\
\hline & Diet/hunger & $4(14.8 \%)$ & $1(11.1 \%)$ & $3(16.7 \%)$ \\
\hline & Stimulant use & $3(11.1 \%)$ & $0(0.0 \%)$ & $3(16.7 \%)$ \\
\hline \multirow[t]{3}{*}{ Family factors } & Family routine & $16(59.3 \%)$ & $5(55.6 \%)$ & $11(61.1 \%)$ \\
\hline & Parents' work schedule & 7 (25.9\%) & $3(33.3 \%)$ & $4(22.2 \%)$ \\
\hline & Adapting to child/coping & $3(11.1 \%)$ & $0(0.0 \%)$ & $3(16.7 \%)$ \\
\hline \multirow{3}{*}{$\begin{array}{l}\text { Children's disability/disease-related } \\
\text { factors }\end{array}$} & Diagnosis/comorbidity & $14(51.9 \%)$ & $0(0.0 \%)$ & $14(77.8 \%)$ \\
\hline & Medication use & $13(48.1 \%)$ & $1(11.1 \%)$ & $12(66.7 \%)$ \\
\hline & Sleep problems & $9(33.3 \%)$ & $8(88.9 \%)$ & $1(5.6 \%)$ \\
\hline \multirow[t]{3}{*}{ Environmental factors } & Light/sunlight & $6(22.2 \%)$ & $1(11.1 \%)$ & $5(27.8 \%)$ \\
\hline & Noise & $5(18.5 \%)$ & $1(11.1 \%)$ & $4(22.2 \%)$ \\
\hline & Quality of sleeping space & $3(11.1 \%)$ & $1(11.1 \%)$ & $2(11.1 \%)$ \\
\hline \multirow{3}{*}{$\begin{array}{l}\text { Adults' responsibility for } \\
\text { children's sleep }\end{array}$} & Parents' responsibility & $4(14.8 \%)$ & $1(11.1 \%)$ & $3(16.7 \%)$ \\
\hline & Family's responsibility & $2(7.4 \%)$ & $0(0.0 \%)$ & $2(11.1 \%)$ \\
\hline & Physicians' responsibility & $3(11.1 \%)$ & $2(22.2 \%)$ & $1(5.6 \%)$ \\
\hline \multirow[t]{10}{*}{ Perceptions of good sleep } & Feeling next day & $14(51.9 \%)$ & $5(55.6 \%)$ & $9(50.0 \%)$ \\
\hline & Interrupted sleep or not & $9(33.3 \%)$ & $3(33.3 \%)$ & $6(33.3 \%)$ \\
\hline & Quality of sleep & $6(22.2 \%)$ & $2(22.2 \%)$ & $4(22.2 \%)$ \\
\hline & Quantity of sleep & $8(29.6 \%)$ & $4(44.4 \%)$ & $4(22.2 \%)$ \\
\hline & Ideal sleep duration for children aged & & & \\
\hline & $<5$ years old was $\geq 10$ hours & $25(92.6 \%)$ & $8(88.9 \%)$ & $17(94.4 \%)$ \\
\hline & $6-12$ years old: $9-10$ hours & $20(74.1 \%)$ & $6(66.7 \%)$ & $14(77.8 \%)$ \\
\hline & 13-18 years old: 8 hours & $14(51.8 \%)$ & $5(55.5 \%)$ & $9(50.0 \%)$ \\
\hline & Waking up on one's own & $4(14.8 \%)$ & $2(22.2 \%)$ & $2(11.1 \%)$ \\
\hline & Bedtime & $2(7.4 \%)$ & $2(22.2 \%)$ & $0(0.0 \%)$ \\
\hline \multirow[t]{2}{*}{ Parental distress } & Anxiety & $6(22.2 \%)$ & $4(44.4 \%)$ & $2(11.1 \%)$ \\
\hline & Frustration & $3(11.1 \%)$ & $3(33.3 \%)$ & $0(0.0 \%)$ \\
\hline
\end{tabular}

in Chile, in relation to sleep. Several participants believed that noise was an environmental factor affecting sleep health. In general, participants perceived that sleeping environment quality was important.

\section{Adults' responsibilities for children's sleep}

Some caregivers believed that health professionals should help with their children's sleep problems. Caregivers expressed a desire to rely on physicians who take responsibility. They believed that health professionals could provide sleep advice and prescribe sleep medications. In contrast, rehabilitation providers believed that parents and families should take responsibility for their children's sleep hygiene. Rehabilitation providers expressed the opinion that it should be parents' or families' responsibilities to create a routine for children and to enforce sleeping rules.

\section{Perceptions of good sleep}

Most participants believed that good sleep should produce energized feelings the next day and featured: an early bedtime; no interruptions; long sleep; high sleep quality; and waking up on one's own. Some caregivers perceived the importance of early bedtime and quiet bedtime activities (e.g., book reading). Both caregivers and rehabilitation providers believed that the appropriate amount of sleep was important, depending on children's 
Table 3 Themes, codes, and representative quotes from 27 focus group participants

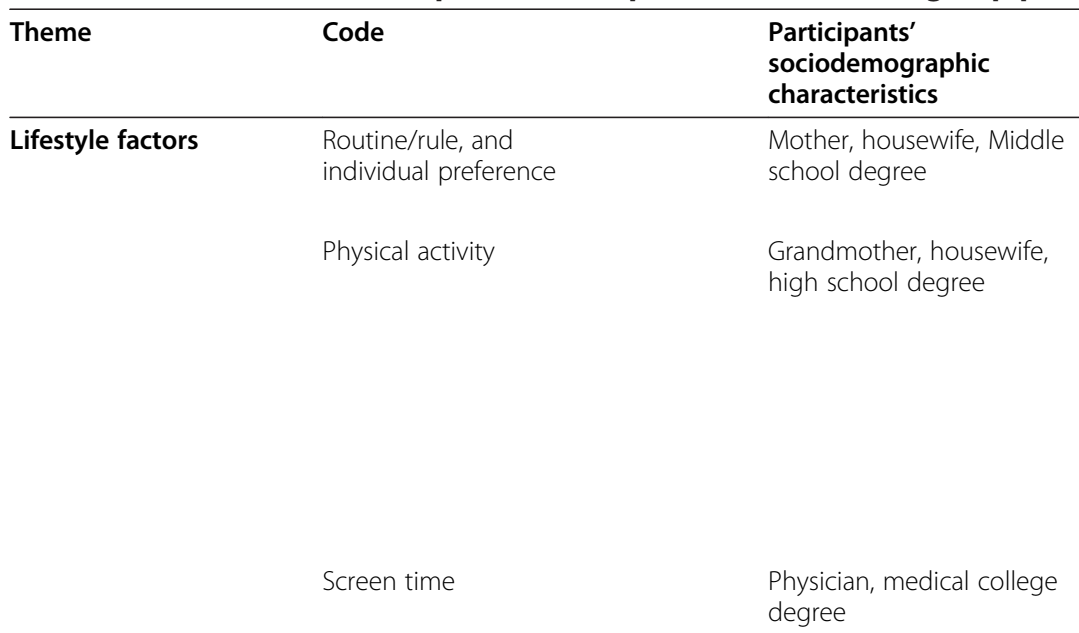

Representative quotes ciodemographic Mother, housewife, Middle "I think they get used to their school schedule, because Diego, even though it is a weekend he will be up at 8." degree

"When my grandson was a year and a half old he didn't sleep at night nor during the day, we put him to bed at 9:00 and he would fall asleep at 10:00 but he wouldn't fall asleep so that's when the doctor started him on melatonin, because a child that doesn't walk and spends most of the day on the floor has very little activity, he doesn't get tired, we took him out for walks but it was the same, we would get home and he would sleep for an hour, we were going crazy."

"I think that school children are not sleeping enough, well, parents do not have the same control as before, for example, they stay on the Internet, on Facebook at night and I have seen with my own children that their friends are connected at 3 in the morning, I mean there are people who stay on line all night and they are not sleeping."

Diet

Stimulant use

Family factors

Family routine

Parents' work schedule

Adapting to child/coping

Children's disability/ disease-related factors

\section{Diagnosis/comorbidity}

Medication use

Sleep problems
Mother, engineer, college degree

"But actually what wakes us all up is our appetite, I mean, one of the kids gets hungry and right ways they are downstairs drinking juice or looking for something to eat."

Physician, medical college degree

Mother, public employee, college degree

Physician, medical college degree

Physical therapist, college degree

Psychologist, college degree

Speech therapist, college degree

Mother, engineer, college degree "...it is very common now to see those popular coffee machines all over the place, and one sees school kids and adolescents in their first stages of adolescence freely consuming this, and one knows that this has an effect on sleeping, where the sleep is maintained and should be a way of resting and one sees them drinking coffee."

"...things that influence the issue of sleep for my son is family organization... in my particular case this structure is a bit broken, because as of 5 months his father is working in another place."

"Yes, because sometimes the ones who work on shifts for example, one sees that the routine of the child is different on the days when the father is not home than on the 7 days when the father is home, right? On the week where the father is not home the schedules are met by the person in charge, in this case the mother who does not work on shifts..."

"What happens in society is that there is a tendency for parents to adapt to the child when they have special needs, a routine is made, and if they have to go to bed they have to go to bed, if they have to wake up early they must wake up early."

"...in the kids with attention disorders, who are hyperactive, who undergo treatments that make them very active during the day, but at night it's like they get unplugged and fall dead asleep and do not wake up, I would think that in that particular sleep it is a very rested one and sufficiently long."

"... if the medications influence their dreams, it is possible that their sleep will be interrupted and will need more hours in order to rest."

"My kids have nightmares, they talk and wake up scared, there aren't any other sounds they only 
Table 3 Themes, codes, and representative quotes from $\mathbf{2 7}$ focus group participants (Continued)

Environmental factors

Light

Noise

Quality of sleeping space

Responsibility

Parents' responsibility

Family's responsibility

Physicians' responsibility

Feeling next day

sleep

Interrupted sleep
Quality of sleep
Quantity of sleep
Ideal sleep duration for children
Waking up on one's own

Bedtime

Anxiety speak once in a while, they sit up but that's it, sometimes they wake up crying, the one in the middle is always more scared."

Special education teacher, "I think that there are many factors, a set of things, college degree the environment at home may be one, the rules at home. For example, now those of us in Magellan have more light, at 10:00 pm it's still clear. This may affect a child's sleep routine."

Mother, unemployed, high "Well in my case, if there is any sort of noise she school degree wakes up."

Mother, housewife, high school degree

"The environment is fundamental and the other thing I think the child should have space, comfort, tranquility and for example the main thing is a good bed, the proper mattress, because if the child has a bad bed he won't sleep properly."

Special education teacher, "A warm room, a comfortable bed and comfortable college degree sheets, and no worries because when you have worries it doesn't allow you to sleep well"

Physical therapist, college "One can give a wide range of possibilities, but degree the parents must choose."

Physician, medical college "Yes, it literally is a frequent question when you degree are a doctor and the reality of the child will show and of the $95 \%$ that do not have a problem or a cause, arrange to have epilepsy or another disorder. The problem is in inadequate acts, and until the family understands that it is because of their actions, it is difficult to make changes, but to complain and not accept it even though we try to show them different way of what is not functioning well even though they are suffering because there are families that have almost separated because usually it is one person that assumes all responsibilities because the other has to rest for work and as the other has to stay home."

Physician, medical college "[Caregivers] want a magic solution, that we give degree them something so the child will sleep and they can count on this to make the child go to sleep when she needs the child to go to sleep."

Physical therapist, college "I think bad sleep and good sleep have to do with degree the feeling that you have when you wake up, you feel that you rested, you feel that it was restful for you, you feel you can start the day well or it is hard to start the day, or you feel you needed more hours."

Mother

"That I get woken up a few times during the night."

Physical therapist, college "A good sleep is a sleep that reaches all stages of degree restful sleep."

Mother, high school degree

"I think good sleep has to do with time and quantity..."

Rehabilitation provider, college degree

Rehabilitation provider, technical school degree

(as for adolescents aged 13-18 years) "yes, 8 hours, it's like adult sleep."

"A good sleep is when I wake up without an external factor like an alarm clock or something like that, it doesn't happen much, but when it does it means that you slept enough, you wake up automatically."

"If I go to bed late, I will be tired during the day and for example if I put them to bed late I think they too will be tired."

Mother, housewife, high school degree
"Well I have to wake up Anna, because she doesn't wake up by herself...if she has to go to school, and as you say I make her more nervous, 


\section{Table 3 Themes, codes, and representative quotes from $\mathbf{2 7}$ focus group participants (Continued)}

\begin{tabular}{|c|c|c|c|}
\hline & & & $\begin{array}{l}\text { because at } 9 \text { when I put her to bed I'm nervous } \\
\text { because she has to go to bed so I make her hurry, } \\
\text { really I pressure her, in the mornings I pressure } \\
\text { her to get up, because she doesn't get up alone." }\end{array}$ \\
\hline & Frustration & $\begin{array}{l}\text { Mother, housewife, high } \\
\text { school degree }\end{array}$ & $\begin{array}{l}\text { "My husband and I 'Dave go to bed, Dave go to } \\
\text { sleep, 1, 2, 3' and I go over there and no, he hides, } \\
\text { he goes round one thing or another, but tell him } \\
\text { stories no, I only scream." }\end{array}$ \\
\hline \multirow[t]{5}{*}{ Coping strategies } & Staying with child & $\begin{array}{l}\text { Mother, public employee, } \\
\text { college degree }\end{array}$ & $\begin{array}{l}\text { "I accompany him for a while, if I have something } \\
\text { to do I tell him and I leave him alone, but if I don't, } \\
\text { I stay with him." }\end{array}$ \\
\hline & Sleep medication use & $\begin{array}{l}\text { Grandmother, housewife, } \\
\text { high school degree }\end{array}$ & $\begin{array}{l}\text { "First as a grandmother, I used to cover him with a } \\
\text { blanket, and since he didn't fall asleep the doctor } \\
\text { gave him } 2 \text { melatonin." }\end{array}$ \\
\hline & Bathing & $\begin{array}{l}\text { Mother, housewife, high } \\
\text { School degree }\end{array}$ & "Give him a bath." \\
\hline & $\begin{array}{l}\text { Story-telling, comforting, and/or } \\
\text { affection }\end{array}$ & Mother, college degree & $\begin{array}{l}\text { "Tell them stories, show them affection so they } \\
\text { can relax." }\end{array}$ \\
\hline & Watching television/movies & $\begin{array}{l}\text { Mother, housewife, high } \\
\text { school degree }\end{array}$ & $\begin{array}{l}\text { "I have been noticing that Anna goes to bed and } \\
\text { stays with the television on, even if it's really low, } \\
\text { she falls asleep faster than when I turn off the lights } \\
\text { and tell her to go to sleep, it takes her around } \\
45 \text { minutes, but with the television on it takes } \\
15 \text { to } 20 \text { minutes." }\end{array}$ \\
\hline \multirow[t]{3}{*}{$\begin{array}{l}\text { Sleep management } \\
\text { advice from health } \\
\text { providers }\end{array}$} & Establish sleeping routine & $\begin{array}{l}\text { Special education teacher, } \\
\text { college degree }\end{array}$ & $\begin{array}{l}\text { "Yes in the teacher-parent meeting, I mentioned } \\
\text { that children were sleepy and I advised parents } \\
\text { to create a sleeping routine, so the learning } \\
\text { process was effective." }\end{array}$ \\
\hline & Control use of electronics & $\begin{array}{l}\text { Physical therapist, college } \\
\text { degree }\end{array}$ & $\begin{array}{l}\text { "For example, too much computer use prior to } \\
\text { going to bed, too much television, which are } \\
\text { obviously stimulating, before bedtime." }\end{array}$ \\
\hline & Control stimulant use & $\begin{array}{l}\text { Physical therapist, college } \\
\text { degree }\end{array}$ & $\begin{array}{l}\text { "Food also, soft drinks, for example, there are } \\
\text { children who cannot sleep, and you can tell he } \\
\text { had a liter of coke, then obviously he is going } \\
\text { to be really active." }\end{array}$ \\
\hline
\end{tabular}

ages. Most participants believed that children $<5$ years of age should sleep at least 10 hours. However, more than two-thirds of caregivers and rehabilitation providers believed that children 6-12 years of age need 9-10 hours of sleep. Fifty percent of caregivers and rehabilitation providers believed that adolescents 13-18 years of age only need 8 hours of sleep.

\section{Parental distress about children's sleep problems}

Several caregivers reported adverse emotional responses due to children's sleep problems, such as anxiety and frustration. A mother described: "My husband and I always say: 'Dave go to bed, Dave go to sleep, 1, 2, 3' and I go over these and no, he hides, he goes round one thing or another".

We also examined caregivers' coping strategies with children's sleep problems and sleep management advice from rehabilitation providers (Table 4). Caregivers reported using various methods to help children fall asleep, including staying with children, using sleep medicine, bathing, telling stories, and/or watching television or movies during bedtime. Some caregivers would allow the children to watch television/movies to deal with sleep problems.

Rehabilitation providers perceived that the use of electronic devices prior to bedtime was related to poor sleep, and believed that the control of television/internet use and stimulant use and the establishment of sleep routines were essential. As one special education teacher stated: "Yes, in the teacher-parent meeting, I mentioned that children were sleepy and I advised parents to create a sleeping routine, so the learning process was effective." One participant mentioned the control of stimulant use: "...there are children who cannot sleep, and you can tell he had a liter of coke, then obviously he is going to be really active".

\section{Discussion}

Focus group participants identified 7 themes related to children's sleep, such as lifestyle behaviors, family factors, and children's disabilities or comorbidities. Caregivers reported using various methods to help children 


\begin{tabular}{|c|c|c|c|c|}
\hline Theme & Code & $\begin{array}{c}\text { Total quotes } \\
\text { (total: } 27) \\
\mathrm{N}(\%) \\
\end{array}$ & $\begin{array}{c}\text { Caregivers } \\
\text { (total: 9) } \\
\text { N (\%) } \\
\end{array}$ & $\begin{array}{c}\text { Rehabilitation providers } \\
\text { (total: 18) } \\
\mathrm{N}(\%)\end{array}$ \\
\hline \multirow[t]{5}{*}{ Caregivers' coping strategies } & Staying with child & $3(33.3 \%)$ & $3(33.3 \%)$ & - \\
\hline & Using sleep medication & $2(22.2 \%)$ & $2(22.2 \%)$ & - \\
\hline & Bathing & $2(22.2 \%)$ & $2(22.2 \%)$ & - \\
\hline & Story-telling, comforting, affection & $2(22.2 \%)$ & $2(22.2 \%)$ & - \\
\hline & Watching television/movie & $2(22.2 \%)$ & $2(22.2 \%)$ & - \\
\hline \multirow{3}{*}{$\begin{array}{l}\text { Rehabilitation providers' } \\
\text { sleep management advice }\end{array}$} & Establish sleeping routine & $5(27.8 \%)$ & - & $5(27.8 \%)$ \\
\hline & Control use of electronics & $4(22.2 \%)$ & - & $4(22.2 \%)$ \\
\hline & Control stimulant use & $1(5.6 \%)$ & - & $1(5.6 \%)$ \\
\hline
\end{tabular}

fall asleep during bedtime, some of which are inconsistent with good sleep hygiene practices, such as staying with children, watching TV/movies, and using sleep medicine. In contrast, sleep management advice from rehabilitation providers was highly appropriate, and included control of television/internet and stimulant use, and the establishment of sleep routines for children. To our knowledge, this is the first study to examine attitudes, beliefs, knowledge, and perceptions about children's sleep from both caregivers and rehabilitation providers of children with disabilities. The observations that caregivers and rehabilitation providers had opposing perspectives regarding the influences of lifestyle characteristics such as electronics, coffee consumption, and medication use on child sleep, and that most individuals had high levels of concern over children's sleep but often under-estimated sleep needs of children may be of fundamental importance for informing the design of intervention programs aimed at improving sleep health among children with disabilities.

Various factors may play important roles in children's sleep [14]. We found that caregivers exhibited awareness of behavioral, environmental, and family factors. Most caregivers realized that family schedules and routines, as well as sleeping space and noise, were related to children's sleep. Caregivers and rehabilitation providers believed that sleep duration and sleep quality were important determinants of good sleep. However, many caregivers and health professionals endorsed fewer than the ideal amount of sleep hours for school-aged children, indicating that they may have inappropriate perceptions of sleep needs for children. Our previous study reported that school-aged children need more sleep than the amounts that participants perceived as ideal [15]. Individuals from divergent cultures may have different perceptions and views concerning the nature and importance of sleep. We note that investigators have documented cultural differences in sleep attitudes and beliefs across populations $[16,17]$.
Rehabilitation providers expressed particular concern about the effects of electronics and stimulant use on children's sleep. Although caregivers believed that behavioral factors were related to children's sleep, none of them mentioned stimulant use as a possible influence. This suggests that caregivers may be unaware of the connection between stimulant beverage consumption and poor sleep. Caffeine consumption is becoming common among children and youths globally $[18,19]$. Our recent study showed that caffeinated beverages and other stimulant use were significantly associated with poor sleep among college students in Chile [18]. Increasing evidence has also shown that television viewing and computer use are related to too little sleep for children $[20,21]$. The National Sleep Foundation Sleep in America Poll reported that caffeine intake and the use of new technology are associated with shortened sleep among US children [21]. Our study underscores the need to educate children and caregivers about the influence of caffeine consumption and screen time on sleep health. Educational intervention programs are needed to help parents understand that lifestyle behaviors may be related to sleep health.

Children with disabilities are at a higher risk of sleep problems than children without disabilities [9,22]. Parents of children with disabilities often report that children have difficulty falling asleep, restless sleep, snoring, and nocturnal awakenings $[23,24]$. In our study, most caregivers reported that their children had nightmares and nocturnal awakenings. It has been reported that nightmares and sleep disturbances are common among children with post-traumatic stress disorder or childhood trauma $[25,26]$. It is vital that caregivers have an appropriate understanding of children's disabilities and comorbidities and the impact of health conditions on children's sleep. Sleep problems have been shown to be associated with deficits in child cognitive and behavioral functioning $[27,28]$.

Caregivers of children with disabilities may experience more stress and depression than caregivers of children 
without disabilities [14,29,30]. Children's sleep disturbances may also adversely affect caregivers, such as mothers $[9,14,22,31]$. Children with disabilities such as ADHD and cerebral palsy are more likely than children without disabilities to wake their parents at night [32]. Children's sleep disturbances can be stressful for parents $[14,33]$. Our study revealed that caregivers had adverse emotional responses such as anxiety and frustration because of children's sleep problems. Maternal depression symptoms have been reported to adversely influence children's sleep [34]. The provision of long-term care for children with disabilities may create great challenges for caregivers and impair their physical and psychological health [4]. Caregiving stress and other health issues from the challenges that caregivers of disabled children experience should be considered in designing effective family-based intervention programs that target children with disabilities, their caregivers, and family members.

There is much uncertainty about the responsibility that caregivers or health professionals should take for children's sleep health. It may be important for both caregivers and health professionals to acknowledge their respective responsibilities for children's sleep. Health professionals are well positioned to provide educational messages to children and caregivers. In this study, 8 out of 18 rehabilitation providers reported having professional experience with sleep medicine or sleep hygiene, whereas only 2 had sleep medicine or sleep hygiene training. Our study highlights the need for health professionals of children with disabilities to acquire necessary sleep medicine and sleep hygiene training to further assist children and their caregivers in promoting healthy sleep.

It has been reported that good sleep hygiene practices are associated with better sleep [35], while parent-set bedtimes are related to earlier bedtimes, longer sleep, and better daytime functioning [36]. In this study, we found that caregivers used various methods to address children's sleep problems. Some caregivers used strategies such as story-telling, evening bathing, or providing comfort and affection to their children as a means for encouraging sleep. However, some caregivers relied on sleep medications or allowed children to watch television until they became bored and finally fell asleep. There are no ideal sleep medications for children; all hypnotic drugs tend to be effective for short periods, but may cause significant adverse effects [14]. Although the American Academy of Sleep Medicine has endorsed the use of melatonin for circadian rhythm sleep disorders [37], melatonin is beneficial only when melatonin secretion is inadequate or inappropriately timed $[14,38,39]$. Because sleep drugs should be prescribed only when appropriately implemented behavioral interventions are ineffective [14], caregivers should acknowledge the importance of promoting children's sleep hygiene and sleep-related lifestyle behaviors such as physical activity and the control of electronics and stimulant use.

Public health recommendations are that children have an established bedtime routine and refrain from caffeine consumption and from sleeping in bedrooms with televisions [35]. The Institute of Medicine (IOM) has recommended that caregivers adopt practices that promote age-appropriate sleep durations, create environments that ensure restful sleep, such as no screen media in rooms where children sleep; encourage practices that promote child self-regulation of sleep [40]. Health and education professionals should be trained in how to counsel parents about their children's age-appropriate sleep durations. It is important for caregivers and families to create a sleep-friendly routine and environment for children. Our findings about the difference between overall recognition of the importance of sleep and the ability of caregivers to articulate positive sleep management strategies underscore the need to implement effective interventions among caregivers to improve child sleep health.

Our study has limitations. We included only 27 focus group participants consisting of caregivers and rehabilitation providers at a rehabilitation center in Chile. The results based on the small sample size from one study site may not be generalizable to other populations. However, such focus group discussions can provide in-depth reflections that reveal common themes among caregivers and rehabilitation providers. In addition, we recruited participants who volunteered to participate in the study. The generalizability of our conclusions may be limited, since study volunteers may be enriched with a population of caregivers and rehabilitation providers who were more knowledgeable than nonparticipants. Despite this, our results suggest that the findings may be valuable for informing the development of intervention programs aimed at improving sleep health among children with disabilities. Further sleep studies in larger and culturally divergent populations are warranted to confirm our findings. Given that interventions can be delivered in various ways (e.g., online resources, face-to-face), future research should address the preferred ways caregivers want to receive information and preferred delivery methods by health professionals.

\section{Conclusions}

This qualitative study showed that caregivers exhibited awareness of behavioral, environmental, and family factors related to children's sleep hygiene. However, many caregivers were unaware of the influences of lifestyle factors such as use of electronics and consumption of caffeinated beverages on children's sleep. Our findings concerning the difference between overall recognition of 
the importance of sleep and the ability of caregivers to articulate positive sleep management strategies underscore the need to implement effective interventions among caregivers to improve child sleep health. While both caregivers and rehabilitation providers recognized the importance of sleep for children's health and functioning, they differed in their understanding of how sleep hygiene practices influence sleep. Rehabilitation providers recognized the negative influence of electronics on sleep and the positive influence of sleep routines. In contrast, caregivers reported use of television/movie watching and stimulants as coping strategies for managing children's sleep problems. Health professionals are well positioned to provide educational messages to children and their caregivers, and further training may improve their ability to assist children with disabilities, and their families in achieving positive health goals. The knowledge gaps identified in this study can inform the design of educational messages and training programs that address caregivers' and providers' perceptions and practices surrounding child sleep.

\section{Abbreviations}

ADHD: Attention-deficit and/or hyperactivity disorder; CPASS: The Chile Pediatric and Adult Sleep and Stress Study.

\section{Competing interests}

The authors declare that they have no competing interests.

\section{Authors' contributions}

XC conceptualized and designed the study, designed the data collection instruments, carried the initial analyses, and drafted the initial manuscript. BG and JCV supervised data collection and critically reviewed the manuscript. MP carried out the field survey and coordinated data collection at the study site. SG carried out the initial analyses. CB supervised data collection and critically reviewed the manuscript. RDZ and SR critically reviewed and revised the manuscript. MAW conceptualized and designed the study, designed the data collection instruments, supervised data collection, and critically reviewed and revised the manuscript. All authors read and approved the final manuscript as submitted.

\section{Acknowledgements}

This research was supported by awards from the National Institutes of Health (National Institute on Minority Health and Health Disparities: T37-MD001449 and National Center for Research Resources (NCRR), the National Center for Advancing Translational Sciences (NCATS): 8UL1TR000170-05) and the National Cancer Institute's Centers for Transdisciplinary Research on Energetics and Cancer (TREC) (U54CA116847). We thank Ms. Adaeze Wosu for helping with the development of focus group discussion questions.

\footnotetext{
Author details

'Department of Epidemiology, Harvard School of Public Health, Boston, MA 02115, USA. ${ }^{2}$ Centro de Rehabilitación Club de Leones Cruz del Sur, Punta Arenas, Chile. ${ }^{3}$ Department of Health Policy \& Management, Columbia University Mailman School of Public, Health, New York, USA. ${ }^{4}$ Spaulding Rehabilitation Hospital, Massachusetts General Hospital Physical Medicine and Rehabilitation Service, Boston, MA 02114, USA. ${ }^{5}$ Division of Sleep and Circadian Disorders, Brigham and Women's Hospital, Boston, MA 02115, USA. ${ }^{6}$ Department of Medicine, Harvard Medical School, Boston, MA 02115, USA.
}

Received: 18 July 2014 Accepted: 25 September 2014 Published: 1 October 2014

\section{References}

1. Disability in the Life Cycle: Invest in Children. In http://www.unicef.org/ disabilities/. Accessed October 1, 2013.

2. Churchill SS, Kieckhefer GM, Landis CA, Ward TM: Sleep measurement and monitoring in children with Down syndrome: a review of the literature, 1960-2010. Sleep Med Rev 2012, 16(5):477-488.

3. Owens JA, Maxim R, Nobile C, McGuinn M, Msall M: Parental and self-report of sleep in children with attention-deficit/hyperactivity disorder. Arch Pediatr Adolesc Med 2000, 154(6):549-555.

4. Raina $\mathrm{P}, \mathrm{O}^{\prime}$ Donnell M, Rosenbaum P, Brehaut J, Walter SD, Russell D, Swinton M, Zhu B, Wood E: The health and well-being of caregivers of children with cerebral palsy. Pediatrics 2005, 115(6):e626-e636.

5. Dabrowska A, Pisula E: Parenting stress and coping styles in mothers and fathers of pre-school children with autism and Down syndrome. J Intellect Disabil Res 2010, 54(3):266-280.

6. Sung V, Hiscock H, Sciberras E, Efron D: Sleep problems in children with attention-deficit/hyperactivity disorder: prevalence and the effect on the child and family. Arch Pediatr Adolesc Med 2008, 162(4):336-342.

7. Hvolby A, Jorgensen J, Bilenberg N: Actigraphic and parental reports of sleep difficulties in children with attention-deficit/hyperactivity disorder. Arch Pediatr Adolesc Med 2008, 162(4):323-329.

8. Galland BC, Elder DE, Taylor BJ: Interventions with a sleep outcome for children with cerebral palsy or a post-traumatic brain injury: a systematic review. Sleep Med Rev 2012, 16(6):561-573.

9. Wayte S, McCaughey E, Holley S, Annaz D, Hill CM: Sleep problems in children with cerebral palsy and their relationship with maternal sleep and depression. Acta Paediatr 2012, 101(6):618-623.

10. Schwartz KA, Pyle SA, Dowd MD, Sheehan K: Attitudes and beliefs of adolescents and parents regarding adolescent suicide. Pediatrics 2010, 125(2):221-227.

11. Patton MQ: Enhancing the quality and credibility of qualitative analysis. Health Serv Res 1999, 34(5 Pt 2):1189-1208.

12. Ryan GW, Bernard HR: Techniques to identify themes. Field Meth 2003, 15:85-109.

13. Shrout PE, Fleiss JL: Intraclass correlations: uses in assessing rater reliability. Psychol Bull 1979, 86(2):420-428.

14. Jan JE, Owens JA, Weiss MD, Johnson KP, Wasdell MB, Freeman RD, Ipsiroglu OS: Sleep hygiene for children with neurodevelopmental disabilities. Pediatrics 2008, 122(6):1343-1350.

15. Chen $X$, Beydoun MA, Wang Y: Is sleep duration associated with childhood obesity? A systematic review and meta-analysis. Obesity (Silver Spring) 2008, 16(2):265-274.

16. Biggs SN, Pizzorno VA, van den Heuvel CJ, Kennedy JD, Martin AJ, Lushington K: Differences in parental attitudes towards sleep and associations with sleep-wake patterns in Caucasian and Southeast Asian school-aged children in Australia. Behav Sleep Med 2010, 8(4):207-218.

17. Short MA, Gradisar M, Lack LC, Wright HR, Dewald JF, Wolfson AR, Carskadon MA: A cross-cultural comparison of sleep duration between US And Australian adolescents: the effect of school start time, parent-set bedtimes, and extracurricular load. Health Educ Behav 2013, 40(3):323-330.

18. Velez JC, Souza A, Traslavina S, Barbosa C, Wosu A, Andrade A, Frye M, Fitzpatrick AL, Gelaye B, Williams MA: The epidemiology of sleep quality and consumption of stimulant beverages among Patagonian Chilean College Students. Sleep Disord 2013, 2013:910104.

19. Lohsoonthorn V, Khidir H, Casillas G, Lertmaharit S, Tadesse MG, Pensuksan WC, Rattananupong T, Gelaye B, Williams MA: Sleep quality and sleep patterns in relation to consumption of energy drinks, caffeinated beverages, and other stimulants among Thai college students. Sleep Breath 2013, 17(3):1017-1028.

20. de Jong E, Visscher TL, HiraSing RA, Heymans MW, Seidell JC, Renders CM: Association between TV viewing, computer use and overweight, determinants and competing activities of screen time in 4- to 13-year-old children. Int J Obes (Lond) 2013, 37(1):47-53.

21. Calamaro CJ, Yang K, Ratcliffe $S$, Chasens ER: Wired at a young age: the effect of caffeine and technology on sleep duration and body mass index in school-aged children. J Pediatric Health Care 2012, 26(4):276-282.

22. Cotton S, Richdale A: Brief report: parental descriptions of sleep problems in children with autism, Down syndrome, and Prader-Willi syndrome. Res Dev Disabil 2006, 27(2):151-161. 
23. Corkum $\mathrm{P}$, Tannock $\mathrm{R}$, Moldofsky $\mathrm{H}$ : Sleep disturbances in children with attention-deficit/hyperactivity disorder. J Am Acad Child Adolesc Psychiatry 1998, 37(6):637-646.

24. Dahl RE, Puig-Antich J: Sleep disturbances in child and adolescent psychiatric disorders. Pediatrician 1990, 17(1):32-37.

25. Oluwabusi OO, Sedky K, Bennett DS: Prazosin treatment of nightmares and sleep disturbances associated with posttraumatic stress disorder: two adolescent cases. J Child Adolesc Psychopharmacol 2012, 22(5):399-402.

26. Gehrman PR, Harb GC: Treatment of nightmares in the context of posttraumatic stress disorder. J Clin Psychol 2010, 66(11):1185-1194.

27. Beebe DW, Ris MD, Kramer ME, Long E, Amin R: The association between sleep disordered breathing, academic grades, and cognitive and behavioral functioning among overweight subjects during middle to late childhood. Sleep 2010, 33(11):1447-1456.

28. Archbold KH, Giordani B, Ruzicka DL, Chervin RD: Cognitive executive dysfunction in children with mild sleep-disordered breathing. Biol Res Nurs 2004, 5(3):168-176.

29. Owens J, Spirito A, Marcotte A, McGuinn M, Berkelhammer L: Neuropsychological and behavioral correlates of obstructive sleep apnea syndrome in children: a preliminary study. Sleep Breath 2000, 4(2):67-78.

30. Chervin RD, Dillon JE, Bassetti C, Ganoczy DA, Pituch KJ: Symptoms of sleep disorders, inattention, and hyperactivity in children. Sleep 1997, 20(12):1185-1192.

31. Bourke-Taylor H, Pallant JF, Law M, Howie L: Relationships between sleep disruptions, health and care responsibilities among mothers of school-aged children with disabilities. J Paediatr Child Health 2013, 49(9):775-782.

32. Ball JD, Tiernan M, Janusz J, Furr A: Sleep patterns among children with attention-deficit hyperactivity disorder: a reexamination of parent perceptions. J Pediatric Psychol 1997, 22(3):389-398.

33. Saxby $H$, Morgan $H$ : Behaviour problems in children with learning disabilities: to what extent do they exist and are they a problem? Child Care Health Dev 1993, 19(3):149-157.

34. Warren SL, Howe G, Simmens SJ, Dahl RE: Maternal depressive symptoms and child sleep: models of mutual influence over time. Dev Psychopathol 2006, 18(1):1-16.

35. Mindell JA, Meltzer LJ, Carskadon MA, Chervin RD: Developmental aspects of sleep hygiene: findings from the 2004 National Sleep Foundation Sleep in America Poll. Sleep Med 2009, 10(7):771-779.

36. Short MA, Gradisar M, Wright H, Lack LC, Dohnt H, Carskadon MA: Time for bed: parent-set bedtimes associated with improved sleep and daytime functioning in adolescents. Sleep 2011, 34(6):797-800.

37. Morgenthaler TI, Lee-Chiong T, Alessi C, Friedman L, Aurora RN, Boehlecke B, Brown T, Chesson AL Jr, Kapur V, Maganti R, Owens J, Pancer J, Swick TJ, Zak R: Practice parameters for the clinical evaluation and treatment of circadian rhythm sleep disorders. An American Academy of Sleep Medicine report. Sleep 2007, 30(11):1445-1459.

38. Wasdell MB, Jan JE, Bomben MM, Freeman RD, Rietveld WJ, Tai J, Hamilton D, Weiss MD: A randomized, placebo-controlled trial of controlled release melatonin treatment of delayed sleep phase syndrome and impaired sleep maintenance in children with neurodevelopmental disabilities. J Pineal Res 2008, 44(1):57-64.

39. Carr R, Wasdell MB, Hamilton D, Weiss MD, Freeman RD, Tai J, Rietveld WJ, Jan JE: Long-term effectiveness outcome of melatonin therapy in children with treatment-resistant circadian rhythm sleep disorders. J Pineal Res 2007, 43(4):351-359.

40. The Institute of Medicine (IOM): http://www.iom.edu/Reports/2011/EarlyChildhood-Obesity-Prevention-Policies/Recommendations.aspx. Accessed October 19, 2013.

doi:10.1186/1471-2431-14-245

Cite this article as: Chen et al:: Attitudes, beliefs, and perceptions of caregivers and rehabilitation providers about disabled children's sleep health: a qualitative study. BMC Pediatrics 2014 14:245.

\section{Submit your next manuscript to BioMed Central and take full advantage of:}

- Convenient online submission

- Thorough peer review

- No space constraints or color figure charges

- Immediate publication on acceptance

- Inclusion in PubMed, CAS, Scopus and Google Scholar

- Research which is freely available for redistribution

Submit your manuscript at www.biomedcentral.com/submit 